\title{
BDNF regulates BIM expression levels in 3-nitropropionic acid-treated cortical neurons
}

\author{
Sandra Almeida, Mário Laço, Teresa Cunha-Oliveira, Catarina R. Oliveira, A. Cristina Rego * \\ Institute of Biochemistry, Faculty of Medicine, and Center for Neuroscience and Cell Biology, University of Coimbra, 3004-504 Coimbra, Portugal
}

\section{A R T I C L E I N F O}

Article history:

Received 15 January 2009

Revised 3 June 2009

Accepted 11 June 2009

Available online 23 June 2009

\section{Keywords:}

BDNF

3-Nitropropionic acid

Mitochondria

Cell death

Neurotrophins

Neurodegeneration

Huntington's disease

\begin{abstract}
A B S T R A C T
3-Nitropropionic acid (3-NP) is an irreversible inhibitor of succinate dehydrogenase that has been used to explore the primary mechanisms of cell death associated with mitochondrial dysfunction and neurodegeneration in Huntington's disease. In this study we investigated the ability of brain-derived neurotrophic factor (BDNF) to suppress mitochondrial-dependent cell death induced by 3-NP in primary cortical neurons. This neurotrophin prevented 3-NP-induced release of cytochrome $c$ and Smac/Diablo, caspase-3-like activity and nuclear condensation/fragmentation. Furthermore, it greatly increased phosphorylation of Akt and MAPK, suggesting the involvement of these signalling pathways in BDNF neuroprotection. Interestingly, BDNF decreased the levels of the pro-apoptotic protein Bim in mitochondrial and total cell lysates through the activation of the MEK1/2 pathway. This effect was due to an increase in the degradation rates of Bim. Our data support an important role for BDNF, in protecting cortical neurons against apoptotic cell death caused by inhibition of mitochondrial complex II.
\end{abstract}

(c) 2009 Elsevier Inc. All rights reserved.

\section{Introduction}

Mitochondrial dysfunction has been linked to the pathogenic mechanisms of several neurodegenerative diseases (Schapira, 2006; Keating, 2008). Neurons are particularly sensitive to alterations in normal mitochondrial function because of their high levels of activity and subsequent need for energy. 3-Nitropropionic acid (3-NP), an inhibitor of succinate dehydrogenase (Coles et al., 1979; Huang et al., 2006), has been widely used to analyse the mechanisms by which metabolic impairment leads to the degeneration of neurons. In particular, 3-NP has been used in the context of Huntington's disease (HD), a hereditary neurodegenerative disease affecting the striatum and the cerebral cortex, since its administration in rodents and nonhuman primates causes abnormal movement, cognitive deficits and neuronal degeneration similar to that seen in HD patients (Beal et al., 1993; Brouillet et al., 1995; Blum et al., 2002). In addition, postmortem brain extracts of HD patients showed reduced activity and expression levels of succinate dehydrogenase (Gu et al., 1996; Browne et al., 1997; Benchoua et al., 2006). Although not entirely elucidated, the mechanisms of 3-NP-induced neurotoxicity involve depletion of ATP, mitochondrial membrane depolarization, dysregulation of intracellular calcium homeostasis, calpain activation, and release of proapoptotic proteins from mitochondria with the consequent activation of caspases and apoptotic pathways (Lee et al., 2002; Bizat et al., 2003;

\footnotetext{
* Corresponding author. Fax: +351 239822776.

E-mail addresses: acrego@cnc.cj.uc.pt, a.cristina.rego@gmail.com (A.C. Rego). Available online on ScienceDirect (www.sciencedirect.com).
}

Almeida et al., 2004, 2006). Although these changes may underlie massive striatal degeneration following 3-NP in vivo administration, a reduction in the activities of complexes I and II was also recently described in the cerebral cortex (Pandey et al., 2008), implicating neuronal dysfunction in this brain area. Indeed, early cortical dysfunction, linked to striatal excitotoxicity and decreased trophic support, appears to have a fundamental role in the onset and progression of HD.

The mitochondrial death pathway is regulated by a fine balance between pro-apoptotic and pro-survival Bcl-2 family members (Cory and Adams, 2002). Pro-apoptotic proteins such as Bax and Bak can disrupt the outer mitochondrial membrane and promote the release of apoptogenic factors such as cytochrome $c$ or Smac/Diablo, an event that ultimately activates the caspase cascade. Apoptosis-inducing factor (AIF) can also be released from the mitochondria, leading to caspase-independent cell death (Susin et al., 1999). In viable cells and under normal conditions, pro-apoptotic proteins are normally repressed by binding to pro-survival proteins such as $\mathrm{Bcl}-2$ and $\mathrm{Bcl}-\mathrm{xL}$. In response to stress, BH3-only proteins, such as Bim, Bid, and Bad, bind to $\mathrm{Bcl}-2$ or Bcl-xL, that then release Bax or Bak. These pro-apoptotic proteins then change their conformation and oligomerize in the mitochondrial membrane to promote cell death (Puthalakath and Strasser, 2002).

Trophic support to neurons largely influences neuronal survival and function. Members of the neurotrophin family, namely brainderived neurotrophic factor (BDNF), have been suggested as therapeutic candidates to treat neurodegenerative disorders because they promote neuronal survival in different lesion models (e.g. Connor and Dragunow, 1998). BDNF is particularly relevant in HD since its transcription (Zuccato et al., 2001) and axonal transport (Gauthier et al., 
2004) are decreased by the presence of mutant huntingtin, affecting the survival of both striatal and cortical neurons. BDNF was previously shown to prevent the death of different populations of striatal projection neurons in a quinolinic acid model of HD (Perez-Navarro et al., 2000; Kells et al., 2004). BDNF was also reported to protect striatal neurons from 3-NP toxicity (Ryu et al., 2004). However, the mechanism used by BDNF leading to neuroprotection is not clear. The effects of BDNF are mainly mediated by TrkB receptor-induced activation of key signalling pathways, including PLC- $\gamma$, Ras/MEK/ MAPK and PI3K/Akt pathways (Huang and Reichardt, 2001). These pathways have been shown to regulate apoptotic cell death by increasing the transcription of neuroprotective proteins such as Bcl-2 (Pugazhenthi et al., 2000) and/or by posttranslational modifications of proteins such as Bad and Bim (del Peso et al., 1997; Scheid et al., 1999; Luciano et al., 2003; Qi et al., 2006).

Taking into account the importance of cortical dysfunction in HD and the potential benefit of BDNF against mitochondrial-driven neuronal degeneration, in this study we analysed the mechanisms by which BDNF protects primary cortical neurons against mild neurotoxicity induced by 3-NP. Our data show that BDNF protects cortical neurons from 3-NP toxicity through the activation of PI3K and MEK1/2 intracellular signalling pathways and the regulation of Bim turnover.

\section{Materials and methods}

\section{Materials}

Neurobasal medium and B-27 supplement were purchased from GIBCO (Paisley, UK). 3-Nitropropionic acid and anti- $\alpha$-tubulin were from Sigma Chemical Co. (St. Louis, MO, USA). N-acetyl-Asp-Glu-ValAsp-p-nitroanilide (Ac-DEVD-pNA) was obtained from Calbiochem (Darmstadt, Germany). BDNF, Wortmannin and LY294002 were from Alomone Labs (Jerusalem, Israel). PD980859, K252a and K252b were from Calbiochem (Darmstadt, Germany). Hoechst 33342 was from Molecular Probes (Eugene, OR, USA). All other reagents were of analytical grade.

\section{Cell culture}

Primary neuronal cultures of rat cerebral cortical neurons were prepared as previously described (Almeida et al., 2004). In brief, cerebral cortices were dissected from fetal rats of the Wistar strain at 16-17 days-old and the cells dissociated. Cortical neurons were resuspended in Neurobasal medium supplemented with $2 \% \mathrm{~B}-27$, $0.2 \mathrm{mM}$ glutamine, $100 \mathrm{U} / \mathrm{mL}$ penicillin and $0.1 \mathrm{mg} / \mathrm{mL}$ streptomycin and cultured in a humidified incubator at $37{ }^{\circ} \mathrm{C}$ and $5 \% \mathrm{CO}_{2}$. After five to seven days in culture, neurons were pre-treated with BDNF ( 50 or $100 \mathrm{ng} / \mathrm{mL}$ ) for $30 \mathrm{~min}$ and further incubated with $0.3 \mathrm{mM}$ 3-NP for $24 \mathrm{~h}$ (3-NP stock solution was prepared in water and brought to $\mathrm{pH} 7.4$ with $\mathrm{NaOH}$ ). Both compounds remained in the medium for the entire duration of the experiment. Where indicated, LY294002 (5 $\mu \mathrm{M})$ and Wortmannin (50 nM), two PI3K inhibitors, PD980859 $(30 \mu \mathrm{M})$ an inhibitor of MEK1/2, K252a (500 nM) and K252b (400 nM), two inhibitors of tyrosine kinase, and cycloheximide $(10 \mu \mathrm{M})$ were incubated $1 \mathrm{~h}$ before the addition of BDNF and all compounds remained in the medium for the entire duration of the experiment.

\section{Caspase protease activity assay}

Caspase-like activity was determined as described previously (Almeida et al., 2004). Briefly, cortical cells were lysed and centrifuged at 14,000 rpm (Eppendorf Centrifuge 5417R) for $10 \mathrm{~min}$. The resulting supernatants were collected and assayed for protein content using the Bio-Rad reagent, according to the manufacturer's instructions. Caspase-3-like activity was measured using Ac-DEVD-pNA as sub- strate. Caspase-like activity was calculated as the increase above the control, for equal protein loading ( $25 \mu \mathrm{g})$.

\section{Nuclear morphology assay}

After treatment, Neurobasal medium was replaced and cortical neurons remained in culture for an additional $24 \mathrm{~h}$ without BDNF or $3-N P$. The cells were fixed with $4 \%$ paraformaldehyde ( $\mathrm{pH} \mathrm{7.4)}$ ) and stained with Hoechst $33342(7.5 \mu \mathrm{g} / \mathrm{mL})$. The nuclear morphology of cortical neurons was analysed by fluorescence microscopy (Zeiss Axioskop 2 microscope). Fluorescence of stained chromatin was examined, and fragmented and/or condensed chromatin scored.

\section{Subcellular fractionation}

\section{Total cell lysate}

Cells were washed twice in ice-cold PBS and resuspended in lysis buffer (in mM: 20 Tris (pH 7.0), $100 \mathrm{NaCl}, 2$ EDTA, 2 EGTA, 1\% Triton $\mathrm{X}$-100) supplemented with $50 \mathrm{mM} \mathrm{NaF}, 1 \mathrm{mM} \mathrm{Na}_{3} \mathrm{VO}_{4}, 1 \mathrm{mM} \mathrm{1,4-}$ dithiothreitol (DTT), $1 \mathrm{mM}$ phenylmethylsulfonyl fluoride (PMSF) and $1 \mu \mathrm{g} / \mathrm{mL}$ protease inhibitor cocktail (chymostatin, pepstatin A, leupeptin and antipain). The lysates were sonicated on ice for $30 \mathrm{~s}$ and centrifuged $(14,000 \mathrm{rpm}$ for $10 \mathrm{~min}$, Eppendorf Centrifuge 5417R) to remove insoluble material. The supernatants were collected and stored at $-80{ }^{\circ} \mathrm{C}$.

\section{Mitochondrial and cytosolic fractions}

Cells were washed twice in ice-cold PBS and resuspended in sucrose buffer (in mM: 250 sucrose, $20 \mathrm{HEPES} / \mathrm{KOH}$ ( $\mathrm{pH} 7.5$ ), $100 \mathrm{KCl}$, $1.5 \mathrm{MgCl}_{2}, 1$ EGTA and $1 \mathrm{EDTA}$ ) supplemented with $1 \mathrm{mM}$ DTT, $0.1 \mathrm{mM}$ PMSF and $1 \mu \mathrm{g} / \mathrm{mL}$ protease inhibitor cocktail on ice. Lysates were homogenized and centrifuged at $500 \times \mathrm{g}$ for $12 \mathrm{~min}\left(4^{\circ} \mathrm{C}\right)$ to pellet the nuclei and cell debris. The supernatant was further centrifuged at $12,000 \times \mathrm{g}$ for $20 \mathrm{~min}$. The resulting pellet (mitochondrial fraction) was resuspended in TNC buffer (10 mM Tris acetate, $\mathrm{pH} 8.0,0.5 \%$ Nonidet P-40, $5 \mathrm{mM} \mathrm{CaCl}_{2}$ ) containing protease inhibitors. TCA (15\%) was added to the $12,000 \times \mathrm{g}$ supernatant and centrifuged at $15,800 \times \mathrm{g}$ for $10 \mathrm{~min}$. The resulting pellet (cytosolic fraction) was resuspended in supplemented sucrose buffer and brought to $\mathrm{pH} 7$ with $\mathrm{KOH}$. Samples were frozen at $-80^{\circ} \mathrm{C}$.

\section{Analysis of mitochondrial adenine nucleotides}

Mitochondrial fractions were prepared and assayed for adenine nucleotides (ATP, ADP and AMP) by separation in a reverse-phase high performance liquid chromatography (HPLC) as described previously (Rego et al., 1997).

\section{Citrate synthase assay}

Citrate synthase (CS) activity was performed at $412 \mathrm{~nm}$ following the reduction of 5,5'-dithio-bis(2-nitrobenzoic acid) in the presence of acetyl-CoA and oxaloacetate, according to Coore et al. (1971). CS activity was expressed in nanomoles per minute per milligram of protein.

\section{Mitochondrial respiratory chain complex activities}

\section{NADH-ubiquinone oxidoreductase assay}

Complex I activity was determined at $340 \mathrm{~nm}$ by following the decrease in NADH absorbance that occurs when ubiquinone is reduced to ubiquinol, according to Ragan et al. (1987). Complex I activity was expressed in nanomoles per minute per milligram of protein and corresponds to the rotenone sensitive rate. The enzyme activity was normalised to citrate synthase activity. 
Succinate-ubiquinone oxidoreductase assay

Complex II activity was monitored at $600 \mathrm{~nm}$ by following the reduction of 6,6-dichlorophenolindophenol (DCPIP) by the ubiquinol formed in the reaction, according to Hatefi and Stiggall (1978). Complex II activity was expressed in nanomoles per minute per milligram of protein and corresponds to the TTFA sensitive rate. The enzyme activity was normalised to citrate synthase activity.

\section{Ubiquinol-cytochrome c reductase assay}

Complex III activity was monitored at $550 \mathrm{~nm}$ by following the reduction of cytochrome $c$ by ubiquinol. The assay was started by adding the sample to the reaction mixture (in mM: $35 \mathrm{~K}_{2} \mathrm{HPO}_{4}, \mathrm{pH} 7.2$, $1 \mathrm{EDTA}, 5 \mathrm{MgCl}_{2}, 1 \mathrm{KCN}$, and $5 \mu \mathrm{M}$ rotenone) containing $15 \mu \mathrm{M}$ cytochrome $c$ and $15 \mu \mathrm{M}$ ubiquinol, at $30^{\circ} \mathrm{C}$. Complex III activity was expressed in rate constant $(k)$ per minute per milligram of protein and normalised to citrate synthase activity.

\section{Cytochrome c oxidase assay}

Complex IV activity was determined at $550 \mathrm{~nm}$ by measuring the oxidation of reduced cytochrome $c$ by cytochrome $c$ oxidase, according to Wharton and Tzagotoff (1967). Complex IV activity was expressed in rate constant $(k)$ per minute per milligram of protein and normalised to citrate synthase activity.

\section{Western blotting analysis}

Subcellular fractions were prepared from cortical neurons as described above and protein content was determined using the BioRad reagent. Equivalent amounts of protein were separated on $10-15 \%$ SDS-PAGE gels and electroblotted onto polyvinylidene difluoride (PVDF) membrane (Amersham Biosciences, Buckinghamshire, UK). After blocking with $5 \%$ skim milk in TBS (25 mM Tris/HCl, pH 7.6, $150 \mathrm{mM} \mathrm{NaCl}) / 0.1 \%$ Tween, for $2 \mathrm{~h}$ (RT), the membranes were incubated with antibodies directed against the denatured form of cytochrome $c$ (PharMingen, 1:500), Smac/Diablo (BD Bioscience, 1:500), Bcl-2 (Santa Cruz Biotechnology Inc., 1:500), AIF (Santa Cruz Biotechnology Inc., 1:1000), P-Akt (Cell Signaling, 1:1000), P-MAPK (Cell Signaling, 1:1000), Akt (BD Bioscience, 1:1000), MAPK (Cell Signaling, 1:1000), and Bim (Stressgen, 1:500) overnight, at $4{ }^{\circ} \mathrm{C}$. The membranes were further incubated with the secondary antibody $(1: 20,000)$ for $2 \mathrm{~h}(\mathrm{RT})$ and the proteins were visualized by using an enhanced chemifluorescence reagent (Amersham Biosciences). The antibody directed against $\alpha$-tubulin $(1: 30,000)$ was used to normalise the amount of protein per lane in total, cytosolic and mitochondrial fractions. Tubulin is an inherent component of mitochondrial membranes (Carré et al., 2002) and its levels did not change in any of the treatments used in this study.

\section{Statistical analysis}

Data were expressed as mean \pm SEM of the number of experiments indicated in the figure legends. Comparisons among multiple groups were performed with one-way analysis of variance (ANOVA) followed by the Tukey-Kramer post-hoc test. Significance was defined as $p<0.05$.

\section{Results}

BDNF prevents mitochondrial-dependent apoptosis induced by 3-NP

In previous work we showed that $0.3 \mathrm{mM} 3-\mathrm{NP}$ activates the mitochondrial apoptotic pathway and that this concentration of 3-NP is not associated with loss of plasma membrane integrity and thus, massive cell death (Almeida et al., 2004). In the present study we determined whether BDNF protected cortical neurons against the apoptotic cell death induced by 3-NP. This concentration of 3-NP inhibited SDH activity by approximately 75\% $(p<0.001)$, but had no effect on mitochondrial ATP, ADP and AMP levels (Table 1). BDNF treatment alone or in combination with 3-NP did not affect SDH activity or adenine nucleotide levels (data not shown). Because the apoptotic process is dependent on the maintenance of the ATP levels in the cell, these results support the occurrence of apoptotic rather than necrotic cell death.

Based on previously reported neuroprotective effects of BDNF (e.g. Perez-Navarro et al., 2000), we analysed the effects of BDNF on caspase- 3 activation induced by $0.3 \mathrm{mM}$ 3-NP. As shown in Fig. 1A, BDNF (100 ng/mL) significantly reduced 3-NP-induced caspase-3 activation by approximately $25 \%(p<0.05)$. However, BDNF at a lower concentration $(50 \mathrm{ng} / \mathrm{mL})$ did not significantly protect neurons from 3-NP-induced toxicity (Fig. 1A). Although the neurotrophin alone seemed to decrease caspase- 3 activation, the data was not statistically significant when compared to untreated neurons.

Because the active form of caspase- 3 can lead to the activation of nuclear DNAses, which then cleave DNA, we tested the effects of BDNF (100 ng/mL) on 3-NP-induced chromatin condensation/ fragmentation. In the presence of 3-NP, there was a decrease of approximately $20 \%(p<0.001)$ in the number of viable cells (showing no condensed and/or fragmented chromatin) relative to untreated neurons (Fig. 1B). Under these experimental conditions, BDNF prevented the decrease in viable cells induced by 3-NP (Fig $1 \mathrm{~B})$.

\section{Activation of PI3K and MEK1/2 signalling pathways upon treatment} with BDNF

To specifically elucidate the mechanism by which BDNF protects neurons from 3-NP-induced cell death, we analysed the activation of the PI3K and MEK1/2 pathways by following the changes in the phosphorylation status of Akt and MAPK (ERK1/2), respectively. BDNF treatment alone significantly increased Akt phosphorylation by $78 \%(p<0.01$, Fig. $2 A)$. In the presence of $3-N P$, BDNF increased Akt phosphorylation to levels greater than $220 \%(p<0.05)$ of untreated cells. This increase was not statistically significant when compared to BDNF alone. Under these experimental conditions, MAPK phosphorylation largely increased in BDNF-treated neurons (p44: $1181 \%, p<0.001$ and p42: $293 \%, p<0.05$, Fig. $2 B$ ). BDNF also elevated the phosphorylation of MAPK in cells treated with 3-NP (p44: 1291\%, $p<0.05$ and $\mathrm{p} 42$ : $262 \%$ ). The incubation of neurons with LY294002 (a PI3K inhibitor) completely blocked Akt phosphorylation, but not the phosphorylation of MAPK in 3-NP plus BDNF-treated neurons. Interestingly, wortmannin, another PI3K

Table 1

Activity of mitochondrial respiratory chain complexes and adenine nucleotides levels.

\begin{tabular}{lll}
\hline & Control & 3-NP \\
\hline Complex activities & $7.774 \pm 1.149$ & $10.64 \pm 2.383$ \\
Cx1/CS & $43.11 \pm 2.270$ & $10.92 \pm 0.268^{* * *}$ \\
Cx2/CS & $7.920 \pm 1.173$ & $7.160 \pm 1.002$ \\
Cx3/CS & $8.197 \pm 0.375$ & $7.360 \pm 0.954$ \\
Cx4/CS & $131.2 \pm 14.71$ & $130.2 \pm 17.76$ \\
Citrate synthase (CS) & & \\
Adenine nucleotides & $22.70 \pm 2.628$ & $22.86 \pm 4.139$ \\
ATP & $14.70 \pm 2.967$ & $8.990 \pm 2.527$ \\
ADP & $8.020 \pm 2.642$ & $5.817 \pm 1.649$ \\
AMP &
\end{tabular}

Cortical neurons were incubated in the absence (control) or in the presence of $0.3 \mathrm{mM}$ 3-NP, for $24 \mathrm{~h}$. Mitochondrial respiratory chain complex (Cx1-4) activities were corrected for citrate synthase activity (CS). Values are given in $\mathrm{nmol} / \mathrm{min} / \mathrm{mg}$ protein, except for $\mathrm{Cx} 3$ and $\mathrm{Cx} 4$, which are given in $\mathrm{k} / \mathrm{min} / \mathrm{mg}$ protein. The adenine nucleotides were measured in mitochondrial fractions prepared as indicated in Materials and methods and the values are given in $\mathrm{nmol} / \mathrm{mg}$ protein. The results were expressed as the mean \pm SEM of 3 distinct experiments, performed in duplicate. Statistical analysis: *** $p<0.001$, compared to untreated neurons. 
A

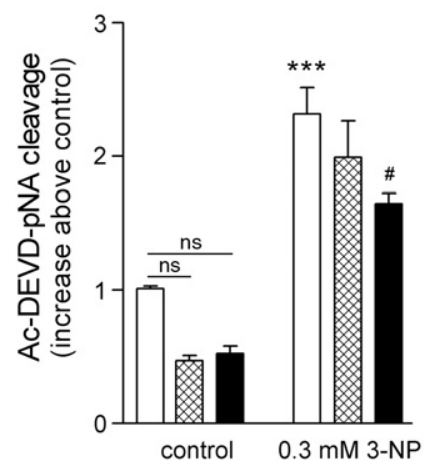

B

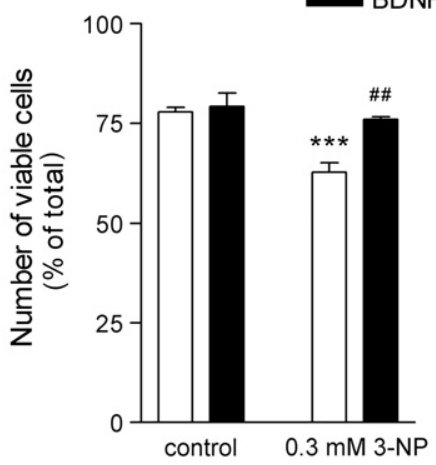

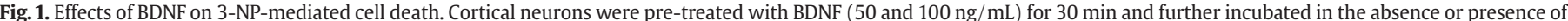

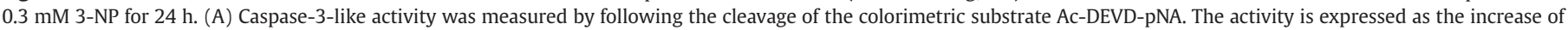

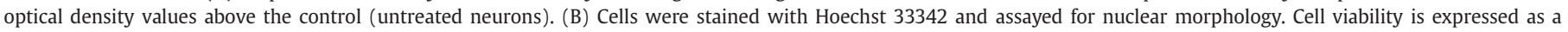

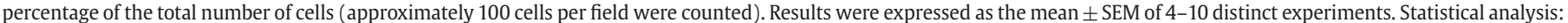
${ }^{* * *} p<0.001$, compared to untreated neurons; ${ }^{\#} p<0.05,{ }^{\# \#} p<0.01$, compared to 3-NP-treated neurons in the absence of BDNF; ns, not significant.

inhibitor, only partially decreased Akt phosphorylation induced by BDNF in the presence of 3-NP and did not affect MAPK phosphorylation (Figs. 2A, B). The concentration of wortmannin used in this study was previously shown to completely block PI3K activity in cortical neurons (Mannella and Brinton, 2006). However, because wortmannin was previously reported to lose effectiveness after $5 \mathrm{~h}$ in serum-containing cultures (Kimura et al., 1994), it is possible that after $24 \mathrm{~h}$ incubation, the PI3K was not maximally
A

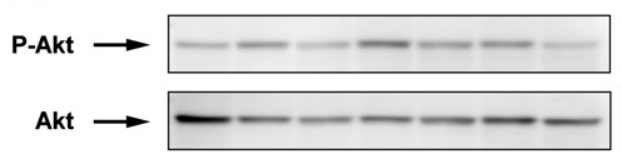

B

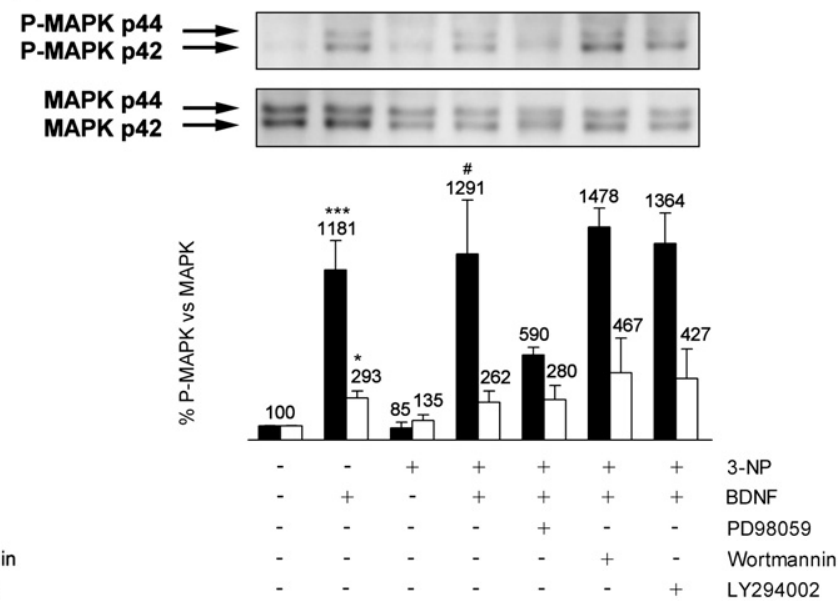

D

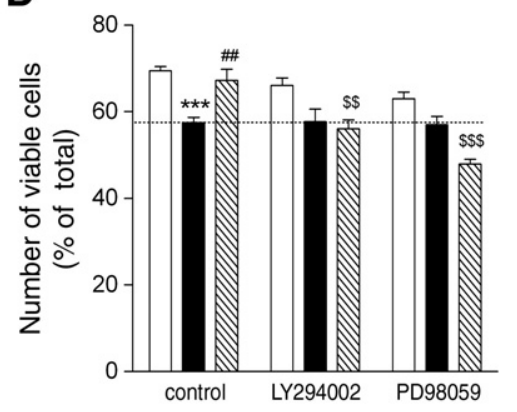

C

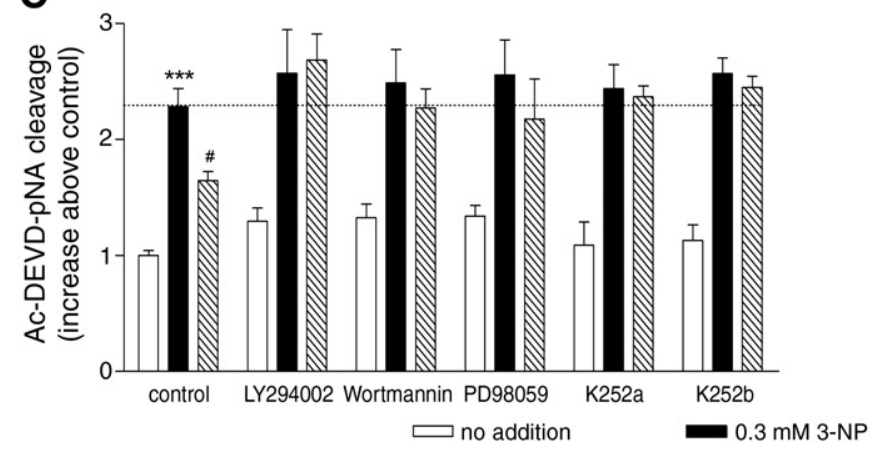

$0.3 \mathrm{mM}$ 3-NP

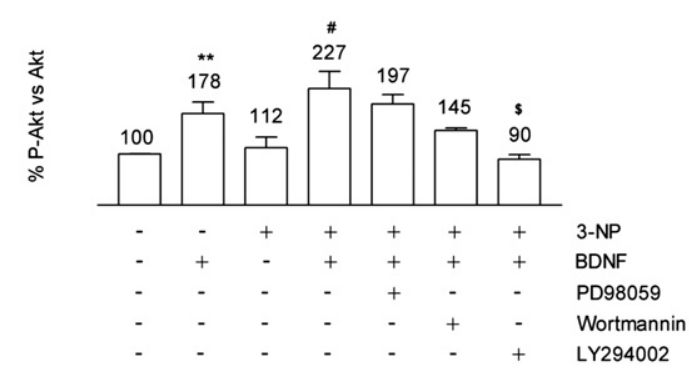

3-NP+BDNF

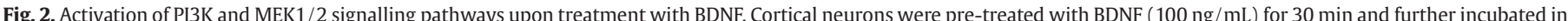

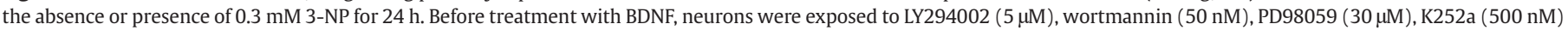

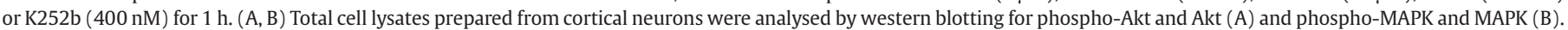

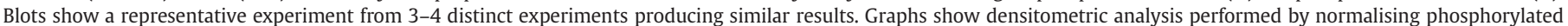

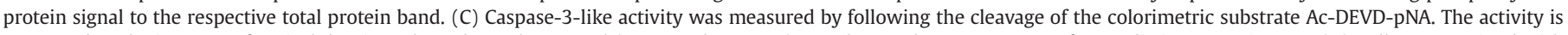

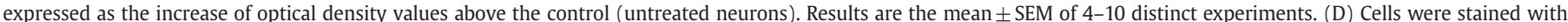

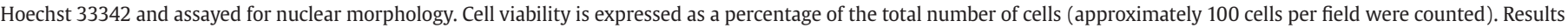

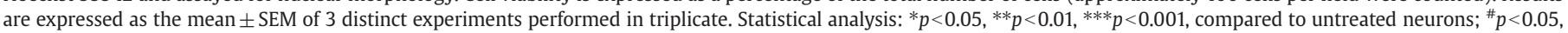
$\# p<0.01$, compared to 3-NP-treated neurons in the absence of BDNF; ${ }^{\$} p<0.05,{ }^{\$ \$} p<0.01,{ }^{\$ \$} p<0.001$, compared to 3-NP-treated neurons in the presence of BDNF. 
inhibited by wortmannin. In contrast, PD98059, a MEK1/2 inhibitor, decreased MAPK phosphorylation by about 55\% in neurons exposed to 3-NP plus BDNF (Fig. 2B), but did not affect Akt phosphorylation (Fig. 2A). These results show that the PI3K and MEK1/2 pathways are independently activated after $24 \mathrm{~h}$ incubation with BDNF in the absence or presence of 3-NP, highly suggesting their involvement in BDNF neuroprotection against 3-NP toxicity. To confirm the involvement of these pathways in BDNF neuroprotection against 3-NP toxicity, we also studied the effect of the two PI3K inhibitors (LY294002 and wortmannin) and the MEK1/2 inhibitor (PD98059), as well as two inhibitors of the Trk receptor tyrosine kinase, K252a and $\mathrm{K} 252 \mathrm{~b}$, on 3-NP-mediated caspase-3 activation in the presence of BDNF (Fig. 2C). Interestingly, all the inhibitors blocked the protective effect of BDNF, suggesting that the activation of each of these kinases is necessary to protect neurons from 3-NP toxicity as assessed by caspase-3 activation. In addition, LY294002 and PD98059 abrogated the protective effect of BDNF on 3-NP toxicity as measured by nuclear morphology (Fig. 2D).

\section{$B D N F$ regulates Bim expression levels in 3-NP-treated cortical neurons}

As shown previously, $0.3 \mathrm{mM} 3$-NP triggers the activation of caspase- 3 through the mitochondrial-dependent pathway (Almeida et al., 2004). Therefore, we next tested whether BDNF could prevent the release of pro-apoptotic proteins from mitochondria of 3-NPtreated neurons. 3-NP caused the release of both cytochrome $c$ and Smac/Diablo from mitochondria (Figs. 3A, C), leading to an increase by about $280 \%(p<0.001)$ and $293 \%(p<0.01)$ of cytochrome $c$ and Smac/Diablo, respectively, in the cytosol (Figs. 3B, D). Treatment with BDNF significantly abrogated the release of both cytochrome $c$ $(p<0.01)$ and Smac/Diablo $(p<0.05)$ from mitochondria. Although not statistically significant, the alterations observed in the mitochondrial fraction for both cytochrome $c$ and Smac/Diablo were correlated with the alterations observed in the cytosolic fraction. In the case of cytochrome $c$, its percentage in the mitochondrial and cytosolic fractions was similar to the values obtained in our previous work (Almeida et al., 2004). We also analysed the release of AIF from
A
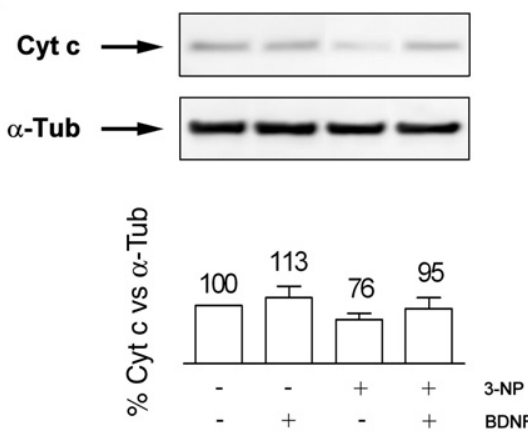

C
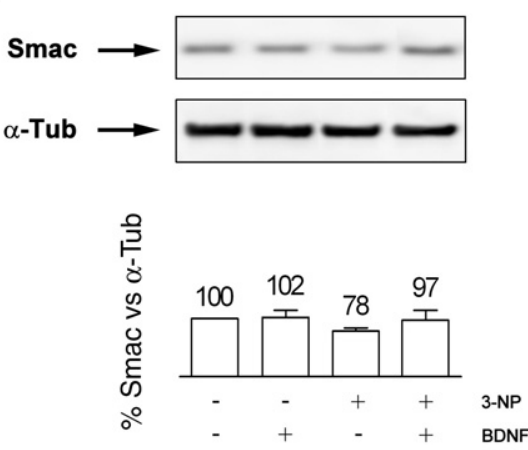

B

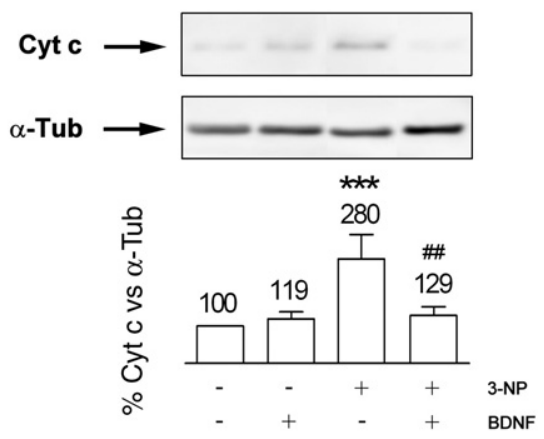

D

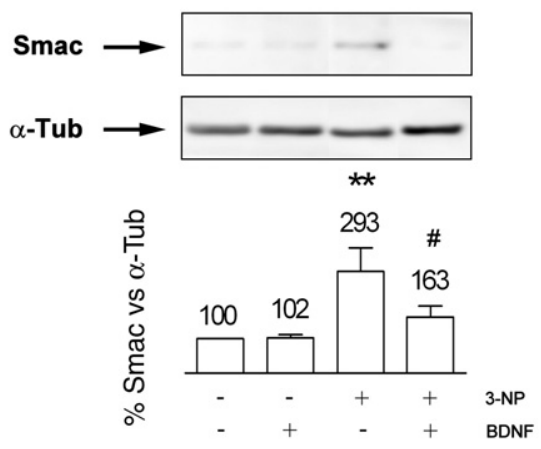

$\mathbf{E}$

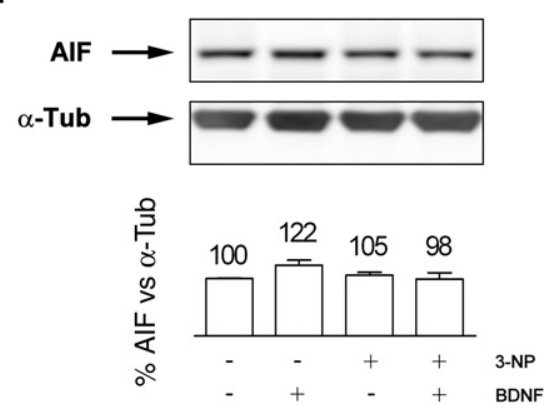

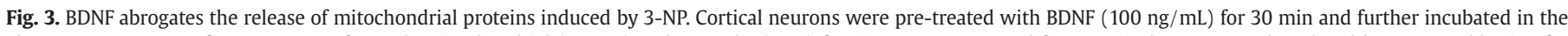

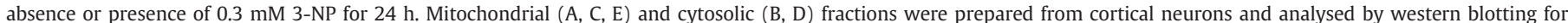

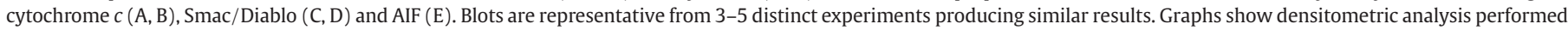

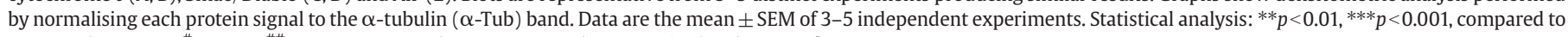
untreated neurons; ${ }^{\#} p<0.05,{ }^{\# \#} p<0.01$, compared to 3-NP-treated neurons in the absence of BDNF. 
mitochondria in the presence of 3-NP. Although we previously demonstrated that treatment of cortical neurons with $1 \mathrm{mM} 3-\mathrm{NP}$ decreased mitochondrial AIF levels (Almeida et al., 2006), the lower concentration of 3-NP $(0.3 \mathrm{mM})$ did not trigger the release of AIF from mitochondria (Fig. 3E).

To further elucidate the mechanism by which BDNF prevents the release of apoptotic proteins from mitochondria and consequently the activation of caspase-3, we evaluated whether BDNF altered the levels of Bcl-2 and Bim, two proteins known to regulate the release of pro-apoptotic proteins from mitochondria (Cory and Adams, 2002). Under the conditions tested, no alterations in mitochondrial or total Bcl-2 levels were observed (Figs. 4A, B), suggesting that the protective effects observed in the presence of BDNF were not dependent on changes in Bcl-2 levels. However, Bim levels in the mitochondria decreased about $30 \%$ by BDNF in the absence or presence $(p<0.05)$ of $3-\mathrm{NP}$ (Fig. $4 \mathrm{C})$. Interestingly, BDNF also decreased total Bim levels by about $36 \%$ in the absence $(p<0.05)$ or presence $(p<0.01)$ of 3-NP (Fig. 4D). 3-NP treatment alone did not significantly change Bim levels in either mitochondrial or total fractions. BDNF-mediated Bim decrease in the presence of 3-NP was completely blocked by the MEK1/2 inhibitor, PD98059 $(40 \mu \mathrm{M})$, whereas the PI3K inhibitor, LY294002, did not significantly affect BDNF-mediated Bim decrease in total cell lysates (Fig. 4D). Because the activation of the Ras/MAPK pathway was previously shown to regulate the degradation of Bim (Ley et al., 2003; Meller et al., 2006), we next tested whether BDNF was able to increase Bim turnover. Neurons were incubated with a high concentration of cycloheximide $(10 \mu \mathrm{M})$, a protein synthesis inhibitor, in the absence or presence of BDNF and/or 3-NP for 2-12 h, and Bim protein levels were measured by western blotting (Fig. 5$)$. The half-life $\left(t_{1 / 2}\right)$ of Bim in untreated cortical cultures following cycloheximide treatment was $2.3 \mathrm{~h}$, a value similar to the half-life found by other authors for these cultures (2.8 h; Meller et al., 2006). In the presence of BDNF or BDNF plus 3-NP, the decrease in Bim expression to basal levels was faster, with half-lives of about $0.5 \mathrm{~h}$ and $0.8 \mathrm{~h}$, respectively. Interestingly, although 3-NP treatment alone did not significantly change Bim levels (Fig. 4) it delayed the normal degradation of the protein $\left(t_{1 / 2} \sim 3.9 \mathrm{~h}\right)$. These data show that the decrease in Bim levels following BDNF treatment is due to active degradation of Bim.

\section{Discussion}

Striatal neurodegeneration has been shown as a major feature in HD. However, brain imaging studies of HD patients showed that cortical sensorimotor degeneration occurs before motor symptoms in the disease (Rosas et al., 2002, 2005). Consistent with this, it has been proposed that alterations in the cerebral cortex of HD patients reduce cortico-striatal trophic support, leading to striatal degeneration (Zuccato et al., 2001). These results highlight the importance of studying the molecular mechanisms underlying cortical dysfunction and developing therapeutic strategies aimed at preventing cortical and, consequently, striatal neuronal death.

Chronic mitochondrial abnormalities have consistently been reported in HD patients (e.g. Beal, 1992) and the 3-NP animal model used to mimic such alterations. Interestingly, chronic systemic administration of 3-NP in rats and non-human primates produces homogeneous inhibition of complex II (SDH) within the brain and not solely the striatum (Brouillet et al., 1998; Bizat et al., 2003), despite evident striatal degeneration associated with behavioural abnormalities that are reminiscent of HD (Beal et al., 1993; Brouillet et al., 1995). Complementing these reports, rats treated with 3-NP showed reductions in mitochondrial complex I activity in the cerebral cortex, in
A

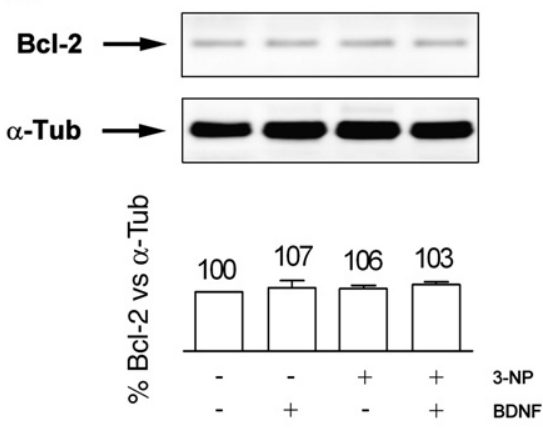

C
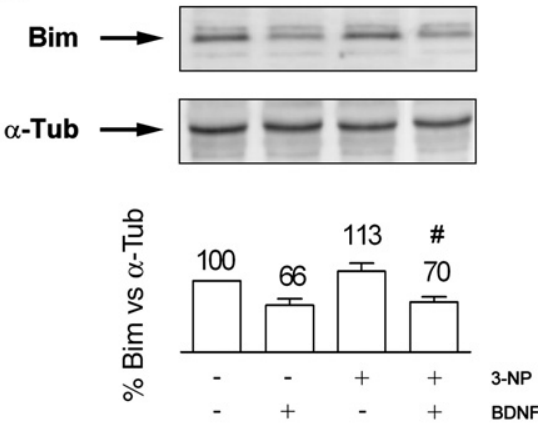

B

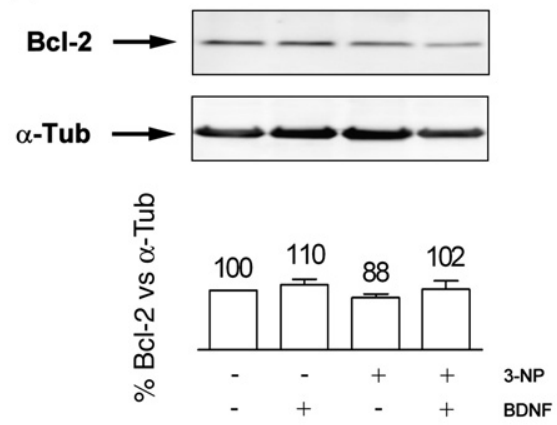

D
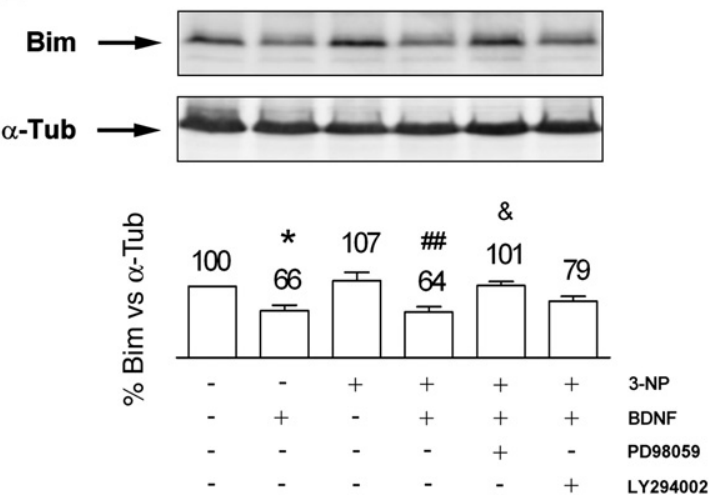

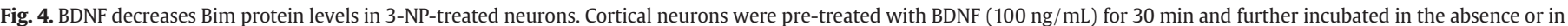

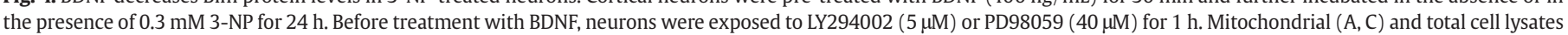

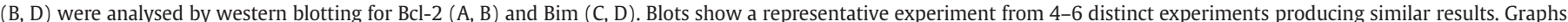

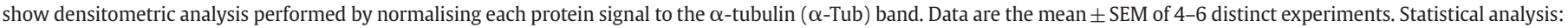

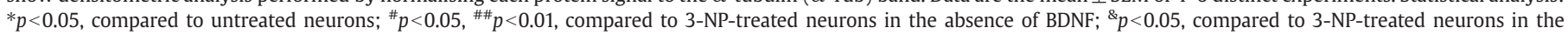
presence of BDNF. 
A

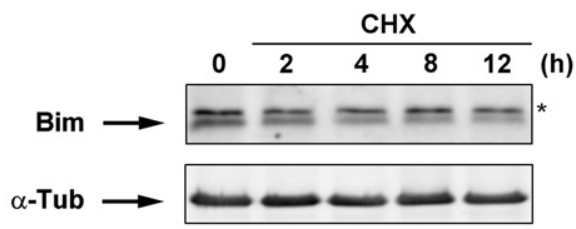

B

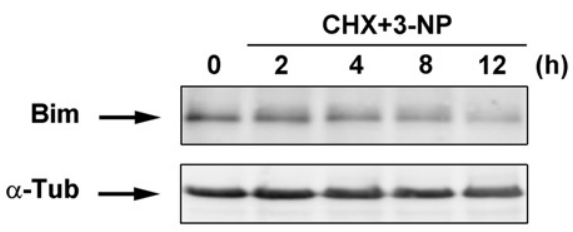

C

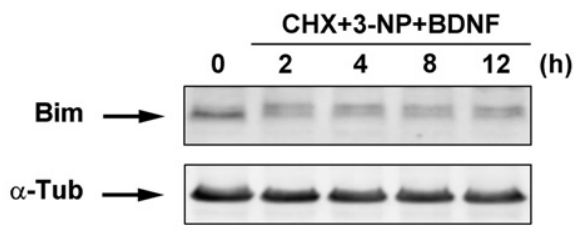

D

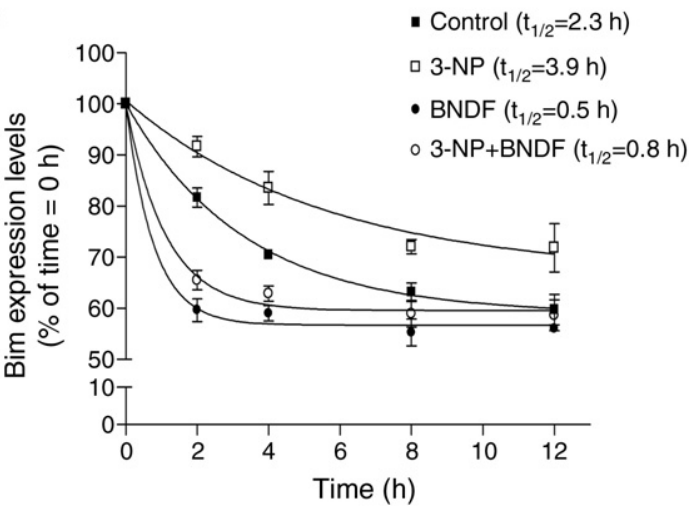

Fig. 5. Effects of 3-NP and BDNF on Bim turnover. Neurons were incubated with cycloheximide (CHX, $10 \mu \mathrm{M}, 1 \mathrm{~h}$ pre-treatment) in the absence or presence of BDNF and/or 3-NP for 2-12 h, and Bim levels were determined by western blotting. (A-C) Representative blots, from three distinct experiments producing similar results are shown. (D) Data obtained from the densitometric analysis, performed by normalising each protein signal to $\alpha$-tubulin ( $\alpha$-Tub), were plotted and fitted to a one-phase exponential decay curve to determine the half-life of Bim (shown in the graph). Data are the mean \pm SEM of three distinct experiments. The upper band $(*)$ visible in panel A appears to be non-specific and disappears in subsequent uses of the Bim antibody.

addition to the irreversible inhibition of complex II and SDH activity, which underlie 3-NP-induced cortico-striatal lesion (Pandey et al., 2008). Thus, the cerebral cortex is implicated as an important target for 3-NP-mediated neuronal dysfunction.

We show that BDNF protects cortical neurons from 3-NP-induced release of apoptotic proteins from mitochondria, caspase-3 activation and chromatin condensation/fragmentation. This protection from apoptotic-like cell death is dependent on the activation of PI3K and MEK1/2 pathways. Our results also demonstrate that BDNF increases Bim turnover, leading to a reduction in both total and mitochondrial Bim levels in a process that is mediated by activation of the MEK1/2 pathway.

In this study we were mainly interested in studying mild 3-NP neurotoxicity, as previously shown (Almeida et al., 2004). Therefore, we used 3-NP at a concentration that while decreasing SDH activity by approximately $75 \%$ did not affect the activity of the other mitochondrial complexes or ATP levels. Indeed, maintenance of cellular ATP levels is important for apoptotic cell death. Our results show that BDNF treatment protects cortical neurons from 3-NP-induced activation of caspase-3, and consequently apoptosis, through the activation of Trk-dependent PI3K and MEK1/2 signalling pathways. Interestingly, as shown by our inhibitor studies, suppression of caspase-3 induction is maximal when both PI3K and MEK1/2 pathways are activated. Because caspase-3 activation induced by 3-NP most likely resulted from the release of cytochrome $c$ and Smac/Diablo from mitochondria, we also evaluated the effect of BDNF treatment on the activation of the mitochondrial-dependent pathway. Our data show that BDNF decreases total Bim levels as well as mitochondriallocalized Bim. Although we did not detect any alteration in $\mathrm{Bcl}-2$ levels, the fact that there is less Bim in the mitochondria after BDNF treatment suggests that more Bcl-2 is available to bind and block Bax and/or Bak oligomerization and the induction of cell death. In support of this, BDNF prevented the release of cytochrome $c$ and Smac/Diablo from the mitochondria and consequently the activation of the mitochondrial apoptotic pathway.

The expression levels of Bim are known to be regulated by both the PI3K/Akt and MEK/MAPK pathways. One mechanism involves the phosphorylation of the forkhead transcription factor by Akt, leading to its cytoplasmic retention by 14-3-3 proteins and a resultant loss of Bim gene activation (Brunet et al., 1999). In a second signalling cascade, Bim phosphorylation by MAPK promotes its subsequent ubiquitination and degradation (Ley et al., 2003). Here we show that BDNF-induced reduction of Bim is dependent on MAPK activation and independent from the activation of the PI3K/Akt pathway, since only PD98059 (a MAPK inhibitor) blocked Bim reduction. Similar results were obtained in neuroblastoma cells exposed to paclitaxel (Li et al., 2007). In these cells, and similar to the present study, BDNF treatment reduced Bim levels in a process regulated by the MAPK pathway and not the PI3K/Akt pathway, while both MAPK and PI3K pathways were involved in BDNF protection of neuroblastoma cells from paclitaxelinduced cell death. In differentiated SH-SY5Y cells, BDNF also decreased the levels of Bim by activation of the MAPK signalling pathway (Zhu et al., 2004).

Our results also support the hypothesis that BDNF affects Bim protein stability by increasing its degradation. The half-life of Bim decreased from $2.3 \mathrm{~h}$ to $0.5 \mathrm{~h}$ in the presence of BDNF and to $0.8 \mathrm{~h}$ in the presence of BDNF plus 3-NP. Interestingly, although 3-NP treatment alone did not significantly change the total Bim expression levels, it delayed the basal degradation of the protein $\left(t_{1 / 2} \sim 3.9 \mathrm{~h}\right)$. Previously, Luciano et al. (2003) showed that Bim phosphorylation is a prerequisite for ubiquitination. Thus, one possible explanation for the delayed degradation of Bim in the presence of 3-NP could be the activation of phosphatases, which would decrease Bim phosphorylation and, consequently, ubiquitination and degradation. Interestingly, there is also evidence that Bim levels are affected by the presence of mutant huntingtin in HD. Recently, it was reported that knock-in mutant STHdhQ111 striatal cells exhibit significantly increased levels of Bim compared to wild type STHdhQ7 cells (Kong et al., 2009). In addition, increased Bim expression levels were found in the brains of 12-week-old R6/2 mice and 30-week-old R6/1 mice (Zhang et al., 2003; García-Martínez et al., 2007). In their study, García-Martínez et al. (2007) showed that only Bim protein and not mRNA levels were enhanced in R6/1 mice, which suggested that mutant huntingtin may lead to increased Bim levels by interfering with its degradation. One possible mechanism by which mutant huntingtin may decrease Bim degradation is through inhibition of BDNF expression (Zuccato et al., 2001). This would result in a decreased activation of the MAPK pathway and resultant Bim phosphorylation. A second possible mechanism would involve the activation of phosphatases by mutant huntingtin, leading to reduced Bim phosphorylation and, subsequently, reduced ubiquitination and degradation of the protein. In support of this hypothesis, knock-in mutant STHdhQ111 striatal cells were recently shown to be more sensitive to cell death due to high levels of calcineurin activation (Xifró et al., 2008).

In summary, our results demonstrate that BDNF plays an important role in the protection of neurons against neurode- 
generation caused by mitochondrial dysfunction due to complex II inhibition. We also found that both PI3K and MAPK pathways seem to be involved in BDNF neuroprotection and that increased Bim degradation underlies BDNF prevention through the MAPK pathway. These findings may be of particular interest in HD since BDNF levels are reduced in the cerebral cortex and striatum of HD patients. Moreover, our data may help to elucidate the protective role of BDNF in cortical neurodegeneration linked to mitochondrial abnormalities.

\section{Acknowledgments}

This work was supported by "Fundação para a Ciência e a Tecnologia” (FCT), Portugal, grant POCI/SAU-NEU/57310/2004.

\section{References}

Almeida, S., Domingues, A., Rodrigues, L., Oliveira, C.R., Rego, A.C., 2004. FK506 prevents mitochondrial-dependent apoptotic cell death induced by 3-nitropropionic acid in rat primary cortical cultures. Neurobiol. Dis. 17, 435-444.

Almeida, S., Brett, A.C., Gois, I.N., Oliveira, C.R., Rego, A.C., 2006. Caspase-dependent and -independent cell death induced by 3-nitropropionic acid in rat cortical neurons. J. Cell. Biochem. 98, 93-101.

Beal, M.F., 1992. Does impairment of energy metabolism result in excitotoxic neurona death in neurodegenerative illnesses? Ann. Neurol. 31, 119-130.

Beal, M.F., Brouillet, E., Jenkins, B.G., Ferrante, R.J., Kowall, N.W., Miller, J.M., Storey, E. Srivastava, R., Rosen, B.R., Hyman, B.T., 1993. Neurochemical and histological characterization of striatal excitotoxic lesions produced by the mitochondrial toxin 3-nitroproprionic acid. J. Neurosci. 13, 4181-4192.

Benchoua, A., Trioulier, Y., Zala, D., Gaillard, M.C., Lefort, N., Dufour, N., Saudou, F. Elalouf, J.M., Hirsch, E., Hantraye, P., Deglon, N., Brouillet, E., 2006. Involvement of mitochondrial complex II defects in neuronal death produced by $\mathrm{N}$-terminus fragment of mutated huntingtin. Mol. Biol. Cell 17, 1652-1663.

Bizat, N., Hermel, J.M., Humbert, S., Jacquard, C., Creminon, C., Escartin, C., Saudou, F, Krajewski, S., Hantraye, P., Brouillet, E., 2003. In vivo calpain/caspase cross-talk during 3-nitropropionic acid-induced striatal degeneration: implication of calpain-mediated cleavage of active caspase-3. J. Biol. Chem. 278, 43245-43253.

Blum, D., Galas, M.C., Gall, D., Cuvelier, L. Schiffmann, S.N., 2002. Striatal and cortical neurochemical changes induced by chronic metabolic compromise in the 3-nitropropionic model of Huntington's disease. Neurobiol. Dis. 10, 410-426.

Brouillet, E., Hantraye, P., Ferrante, R.J., Dolan, R., Leroy-Willig, A., Kowall, N.W., Beal, M.F., 1995. Chronic mitochondrial energy impairment produces selective striata degeneration and abnormal choreiform movements in primates. Proc. Natl. Acad. Sci. U. S. A. 92, 7105-7109

Brouillet, E. Guyot, M-C., Mittoux, V., Altairac, S., Condé, F, Palfi, S., Hantraye, P., 1998. Partial inhibition of brain succinate dehydrogenase by 3-nitropropionic acid is sufficient to initiate striatal degeneration in rat. J. Neurochem. 70, 794-805.

Browne, S.E., Bowling, A.C., MacGarvey, U., Baik, M.J., Berger, S.C., Muqit, M.M., Bird, E.D., Beal, M.F., 1997. Oxidative damage and metabolic dysfunction in Huntington's disease: selective vulnerability of the basal ganglia. Ann. Neurol. 41, 646-653.

Brunet, A., Bonni, A., Zigmond, M.J., Lin, M.Z., Juo, P., Hu, L.S., Anderson, M.J., Arden, K.C., Blenis, J., Greenberg, M.E., 1999. Akt promotes cell survival by phosphorylating and inhibiting a Forkhead transcription factor. Cell 96, 857-868.

Carré, M., André, N., Carles, G., Borghi, H., Brichese, L., Briand, C., Braguer, D., 2002 Tubulin is an inherent component of mitochondrial membranes that interacts with the voltage-dependent anion channel. J. Biol. Chem. 277, 33664-33669.

Coles, C.J., Edmondson, D.E., Singer, T.P., 1979. Inactivation of succinate dehydrogenase by 3-nitropropionate. J. Biol. Chem. 254, 5161-5167.

Connor, B., Dragunow, M., 1998. The role of neuronal growth factors in neurodegenerative disorders of the human brain. Brain Res. Brain Res. Rev. 27, 1-39.

Coore, H.G., Denton, R.M., Martin, B.R., Randle, P.J., 1971. Regulation of adipose tissue pyruvate dehydrogenase by insulin and others hormones. Biochem. J. 125, $115-127$.

Cory, S., Adams, J.M., 2002. The Bcl2 family: regulators of the cellular life-or-death switch. Nat. Rev. Cancer 2, 647-656.

del Peso, L., Gonzalez-Garcia, M., Page, C., Herrera, R., Nunez, G., 1997. Interleukin-3induced phosphorylation of BAD through the protein kinase Akt. Science 278, 687-689.

García-Martínez, J.M., Pérez-Navarro, E., Xifró, X., Canals, J.M., Díaz-Hernández, M. Trioulier, Y. Brouillet, E., Lucas, J. Alberch, J., 2007. BH3-only proteins Bid and Bim (EL) are differentially involved in neuronal dysfunction in mouse models of Huntington's disease. J. Neurosci. Res. 85, 2756-2769.

Gauthier, L.R., Charrin, B.C., Borrell-Pages, M., Dompierre, J.P., Rangone, H., Cordelieres De Mey, J., MacDonald, M.E., Lebmann, V., Humbert, S., Saudou, F., 2004. Huntingtin controls neurotrophic support and survival of neurons by enhancing BDNF vesicular transport along microtubules. Cell 118, 127-138.

Gu, M., Gash, M.T., Mann, V.M., Javoy-Agid, F., Cooper, J.M., Schapira, A.H., 1996 Mitochondrial defect in Huntington's disease caudate nucleus. Ann. Neurol. 39, 385-389.

Hatefi, Y., Stiggall, D.L., 1978. Preparation and properties of succinate: ubiquinone oxidoreductase (complex II). Methods Enzymol. 53, 21-27.
Huang, E.J., Reichardt, L.F., 2001. Neurotrophins: roles in neuronal development and function. Annu. Rev. Neurosci. 24, 677-736

Huang, L.S., Sun, G., Cobessi, D., Wang, A.C., Shen, J.T., Tung, E.Y., Anderson, V.E., Berry, E.A., 2006. 3-nitropropionic acid is a suicide inhibitor of mitochondrial respiration that, upon oxidation by complex II, forms a covalent adduct with a catalytic base arginine in the active site of the enzyme. J. Biol. Chem. 281, 5965-5972.

Keating, D.J., 2008. Mitochondrial dysfunction, oxidative stress, regulation of exocytosis and their relevance to neurodegenerative diseases. J. Neurochem. 104, 298-305.

Kells, A.P., Fong, D.M., Dragunow, M., During, M.J., Young, D., Connor, B., 2004. AAV-mediated gene delivery of BDNF or GDNF is neuroprotective in a model of Huntington disease. Mol. Ther. 9, 682-688.

Kimura, K., Hattori, S., Kauyama, Y., Shizawa, Y., Takayanagi, J., Nakamura, S., Toki, S., Matsuda, Y., Onodera, K., Fukui, Y., 1994. Neurite outgrowth of PC12 cells is suppressed by wortmannin, a specific inhibitor of phosphatidylinositol 3-kinase. J. Biol. Chem. 269, 18961-18967.

Kong, P.J., Kil, M.O., Lee, H., Kim, S.S., Johnson, G.V., Chun, W., 2009. Increased expression of Bim contributes to the potentiation of serum deprivation-induced apoptotic cell death in Huntington's disease knock-in striatal cell line. Neurol. Res. 31, 77-83.

Lee, W.T., Yin, H.S., Shen, Y.Z, 2002. The mechanisms of neuronal death produced by mitochondrial toxin 3-nitropropionic acid: the roles of N-methyl-D-aspartate glutamate receptors and mitochondrial calcium overload. Neuroscience 112, 707-716.

Ley, R., Balmanno, K., Hadfield, K., Weston, C., Cook, S.J., 2003. Activation of the ERK1/2 signaling pathway promotes phosphorylation and proteasomedependent degradation of the BH3-only protein. Bim. J. Biol. Chem. 278, 18811-18816.

Li, Z., Zhang, J., Liu, Z., Woo, C.W., Thiele, C.J., 2007. Downregulation of Bim by brainderived neurotrophic factor activation of TrkB protects neuroblastoma cells from paclitaxel but not etoposide or cisplatin-induced cell death. Cell Death Differ. 14, 318-326.

Luciano, F., Jacquel, A., Colosetti, P., Herrant, M., Cagnol, S., Pages, G., Auberger, P., 2003. Phosphorylation of Bim-EL by Erk1/2 on serine 69 promotes its degradation via the proteasome pathway and regulates its proapoptotic function. Oncogene 22, 6785-6793.

Mannella, P., Brinton, R.D., 2006. Estrogen receptor protein interaction with phosphatidylinositol 3-kinase leads to activation of phosphorylated Akt and extracellular signal-regulated kinase $1 / 2$ in the same population of cortical neurons: a unified mechanism of estrogen action. J. Neurosci. 26, 9439-9447.

Meller, R., Cameron, J.A., Torrey, D.J., Clayton, C.E., Ordonez, A.N., Henshall, D.C., Minami, M. Schindler, C.K. Saugstad, J.A. Simon, R.P., 2006. Rapid degradation of Bim by the ubiquitin-proteasome pathway mediates short-term ischemic tolerance in cultured neurons. J. Biol. Chem. 281, 7429-7436.

Pandey, M., Varghese, M., Sindhu, K.M., Sreetama, S., Navneet, A.K., Mohanakumar, K.P., Usha, R., 2008. Mitochondrial NAD+-linked state 3 respiration and complex-I activity are compromised in the cerebral cortex of 3-nitropropionic acid-induced rat model of Huntington's disease. J. Neurochem. 104, 420-434.

Perez-Navarro, E. Canudas, A.M., Akerund, P. Alberch, J., Arenas, E. 2000. Brainderived neurotrophic factor, neurotrophin-3, and neurotrophin-4/5 prevent the death of striatal projection neurons in a rodent model of Huntington's disease. J. Neurochem. 75, 2190-2199.

Pugazhenthi, S., Nesterova, A., Sable, C., Heidenreich, K.A., Boxer, L.M., Heasley, L.E., Reusch, J.E., 2000. Akt/protein kinase B up-regulates Bcl-2 expression through cAMP-response element-binding protein. J. Biol. Chem. 275, 10761-10766.

Puthalakath, H., Strasser, A., 2002. Keeping killers on a tight leash: transcriptional and post-translational control of the pro-apoptotic activity of BH3-only proteins. Cell Death Differ. 9, 505-512.

Qi, X.J., Wildey, G.M., Howe, P.H., 2006. Evidence that Ser87 of BimEL is phosphorylated by Akt and regulates BimEL apoptotic function. J. Biol. Chem. 281, 813-823.

Ragan, C.I., Wilson, M.T., Darley-Usmar, V.M., Lowe, P.N., 1987. Subfractionation of mitochondria, and isolation of the proteins of oxidative phosphorylation. In: Darley-Usmar, V.M., Rickwood, D., Wilson, M.T. (Eds.), Mitochondria, A Practical Approach. IRL Press, London, pp. 79-112.

Rego, A.C., Santos, M.S., Oliveira, C.R., 1997. Adenosine triphosphate degradation products after oxidative stress and metabolic dysfunction in cultured retinal cells. J. Neurochem. 69, 1228-1235.

Rosas, H.D., Liu, A.K., Hersch, S.M., 2002. Regional and progressive thinning of the cortical ribbon in Huntington's disease. Neurology 58, 695-701.

Rosas, H.D. Hevelone, N.D., Zaleta, A.K., Greve, D.N., Salat, D.H., Fischl, B., 2005. Regional cortical thinning in preclinical Huntington disease and its relationship to cognition. Neurology 65, 745-747.

Ryu, J.K., Kim, J., Cho, S.J., Hatori, K., Nagai, A., Choi, H.B., Lee, M.C., McLarnon, J.G., Kim, S.U., 2004. Proactive transplantation of human neural stem cells prevents degeneration of striatal neurons in a rat model of Huntington disease. Neurobiol. Dis. $16,68-77$

Schapira, A.H., 2006. Mitochondrial disease. Lancet 368, 70-82.

Scheid, M.P., Schubert, K.M., Duronio, V., 1999. Regulation of bad phosphorylation and association with bcl-x(L) by the MAPK/Erk kinase. J. Biol. Chem. 274, 31108-31113.

Susin, S.A., Lorenzo, H.K., Zamzami, N., Marzo, I., Snow, B.E., Brothers, G.M., Mangion, J. Jacotot, E., Costantini, P., Loeffler, M., Larochette, N., Goodlett, D.R., Aebersold, R., Siderovski, D.P., Penninger, J.M., Kroemer, G., 1999. Molecular characterization of mitochondrial apoptosis-inducing factor. Nature 397, 441-446.

Wharton, D.C. Tzagotoff, A., 1967. Cytochrome oxidase from beef heart mitochondria. Methods Enzymol. 10, 245-250. 
Xifró, X., García-Martínez, J.M., Del Toro, D., Alberch, J., Pérez-Navarro, E., 2008. Calcineurin is involved in the early activation of NMDA-mediated cell death in mutant huntingtin knock-in striatal cells. J. Neurochem. 105, 1596-15612.

Zhang, Y., Ona, V.O., Li, M., Drozda, M., Dubois-Dauphin, M., Przedborski, S., Ferrante, R.J., Friedlander, R.M., 2003. Sequential activation of individual caspases, and of alterations in Bcl-2 proapoptotic signals in a mouse model of Huntington's disease. J. Neurochem. 877, 1184-1192.
Zhu, W., Bijur, G.N., Styles, N.A., Li, X., 2004. Regulation of FOXO3a by brain-derived neurotrophic factor in differentiated human SH-SY5Y neuroblastoma cells. Brain Res. Mol. Brain Res. 126, 45-56.

Zuccato, C., Ciammola, A., Rigamonti, D., Leavitt, B.R., Goffredo, D., Conti, L., MacDonald, M.E., Friedlander, R.M., Silani, V., Hayden, M.R., Timmusk, T., Sipione, S., Cattaneo, E., 2001. Loss of huntingtin-mediated BDNF gene transcription in Huntington's disease. Science 293, 493-498. 